\title{
Expression of ATP7B in normal human liver
}

\section{Fanni, L. Pilloni, S. Orrù, ${ }^{\circ}$ P. Coni, C. Liguori, S. Serra, M.L. Lai, A. Uccheddu, ${ }^{\S}$ L. Contu, ${ }^{\circ}$ P. Van Eyken, ${ }^{*}$ G. Faa}

\author{
Dipartimento di Citomorfologia, Divisione di Anatomia Patologica; ${ }^{\circ}$ Cattedra di Genetica Medica, \\ $\left.\S\right|^{\circ}$ Cattedra di Clinica Chirurgica, University of Cagliari, Cagliari, Italy; *Department of Pathology, K.U. \\ Leuven, Leuven, Belgium
}

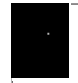

(C)2005, European Journal of Histochemistry

ATP7B is a copper transporting P-type ATPase, also known as Wilson disease protein, which plays a key role in copper distribution inside cells. Recent experimental data in cell culture have shown that ATP7B putatively serves a dual function in hepatocytes: when localized to the Golgi apparatus, it has a biosynthetic role, delivering copper atoms to apoceruloplasmin; when the hepatocytes are under copper stress, ATP7B translocates to the biliary pole to transport excess copper out of the cell and into the bile canaliculus for subsequent excretion from the body via the bile. The above data on ATP7B localization have been mainly obtained in tumor cell systems in vitro. The aim of the present work was to assess the presence and localization of the Wilson disease protein in the human liver. We tested immunoreactivity for ATP7B in 10 human liver biopsies, in which no significant pathological lesion was found using a polyclonal antiserum specific for ATP7B. In the normal liver, immunoreactivity for ATP7B was observed in hepatocytes and in biliary cells. In the hepatocytes, immunoreactivity for ATP7B was observed close to the plasma membrane, both at the sinusoidal and at the biliary pole. In the biliary cells, ATP7B was localized close to the cell membrane, mainly concentrated at the basal pole of the cells. The data suggest that, in human liver, ATP7B is localized to the plasma membrane of both hepatocytes and biliary epithelial cells.

Key words: ATP7B, copper, human liver, Wilson disease.

Correspondence: Daniela Fanni,

Istituto di Anatomia Patologica, Ospedale San Giovanni di Dio Via Ospedale n. 60, 09124 Cagliari, Italy

Tel: +39.070.6092370 - 6092372 - 6092487.

Fax: 39.070 .657882

E-mail: fandan73@virgilio.it

Paper accepted on May 30, 2005

European Journal of Histochemistry

2005; vol. 49 issue 3 (Oct-Dec): 371-378
A TP7B is a 1465 amino acid protein which plays a key role in the normal cellular distribution of copper in liver, kidney, placenta (Petrukhin et al., 1994 ) and brain (Lutsenko et al., 2003). ATP7B belongs to the P-type adenosine triphosphatase family; a family which includes a number of membrane proteins specialized in the transport of cations across cell membranes (Lutsenko and Kaplan, 1995). ATP7B is the transcript of the Wilson disease (WD) gene, and contains five main domains: a distinctive amino-terminal copper-binding region having six metal-binding motifs, GXXCXXC; a transmembrane cation channel, which probably determines the metal specificity of ATP7B (Hou et al., 2001); an ATP domain; a phosphorylation region; a transduction domain responsible for ATP hydrolysis (Terada et al., 1998; Forbes et al., 1999; Riordan and Williams, 2001) (Figure 1). Copper binding occurs via cysteine residues in the metal-binding motif GXXCXXC, six copies of which are present in ATP7B. This motif is present in other metal-binding proteins, such as ZntA, a $\mathrm{Pb}-\mathrm{Zn}-\mathrm{Cd}$-ATPase described in Escherichia Coli (Hou et al., 2001). The putative role of the copper-binding domains is to remove the metal from other copper ligands, such as the cytoplasmic copper chaperones HAHIp (Hung et al., 2002; Larin et al., 1999) and ATOX1 (Hamza et al., 2001; Lutzenko et al., 2003).

But, in which compartment of the cell is ATP7B prevalently located? Previous studies carried out in Hep G2 cell cultures using polyclonal antibodies specific to ATP7B have shown that ATP7B is localized to the Golgi apparatus under low copper conditions (Hung HI, 1997). After adding CuSO4 to the medium, ATP7B was found to redistribute from the Golgi apparatus to the cell membrane, in close proximity to the biliary canaliculus (Roelofsen et al, 2000). Chelation of the excess copper from 
the medium resulted in redistribution of ATP7B to its initial location in the Golgi network (Hung et al., 1997; Schaefer et al., 1999a; Gitlin JD, 2003). The re-distribution of this protein from the Golgi apparatus to the vesicular compartment coincides with copper-induced phosphorylation of ATP7B, whereas the return of ATP7B to the Golgi apparatus is accompained by dephosphorylation of ATP7B in response to copper withdrawal (Vanderwerf et al., 2001). The analysis of human ATP7B expressed in hepatocytes from Long-Evans Cinnamon (LEC) rats, on the other hand, revealed that at least part of the protein is normally expressed not only at the Golgi region, but also at the periphery of the cell, close to the plasma membrane (Nagano et al., 1998).

The aim of this study was to determine the localization of ATP7B in human liver.

\section{Materials and Methods}

\section{Patients}

Surgical specimens from patients with untreated primary liver tumor were provided for this study. The patients underwent surgery in Cagliari and Leuven University hospitals, for reasons other then immunocytochemistry for ATP7B: therefore, no additional punctures were necessary, and written informed consent was obtained from all patients. Specimens obtained from the surrounding liver, all characterized by the absence of cirrhosis, severe fibrosis or significant inflammatory changes, were included in the present study. The patients came from Sardinia and Belgium, from areas with no copper excess either in food or in water.

\section{Embedding procedures and immunolocalization}

A part of each liver biopsy was formalin-fixed, paraffin-embedded and used for routine histological examination. Small liver blocks, which showed at least 4 portal spaces, were snap-frozen in liquid nitrogen-cooled isopentane and stored at $-70^{\circ} \mathrm{C}$ until used for immunohistochemistry.

\section{Antibody}

To generate polyclonal antisera specific to ATP7B, antibodies were raised against the synthetic peptide RQITAREGASRKILSK, corresponding to the NH2-terminal segment of the Wilson disease protein. This sequence was chosen on the basis of a search performed at the Swiss Institute of
Bioinformatics (SIB) using the BLAST network service. This search showed that this sequence is specific, in man, for the P-type ATPase ATP7B. A scan for the same sequence in other animals showed its absence in ATP7B of rats. After immunization of New Zealand white rabbits, antiserum was prepared from whole blood and the IgG fraction was isolated.

Immunohistochemistry was performed using 6-9 $\mu \mathrm{m}$ thick snap-frozen sections. These were placed onto polylysine-coated slides and fixed with acetone for 10 min before the application of the primary and secondary antibody. Next, sections were washed in buffer (PBS pH 7.4 \pm 0.2 ) and, after incubation in biotin blocking solution (Dako; Milan; Italy), they were incubated for 30 min with primary anti-ATP7B antibody. Slides were then washed in buffer, incubated with diluted biotinylated antibody (LSAB2 biotinylated link Dako system; Milan; Italy) for 10 min, washed and incubated in streptavidin-HRP (LSAB2 streptavidin-HRP Dako; Milan; Italy) for 10 min, washed in buffer for 5 min and developed in aminoethylcarbazole (Dako; Milan, Italy). The sections were counterstained with Mayer's hematoxyilin.

We used HepG2 cells as a positive control for human ATP7B since the distribution of ATP7B in these cells is well documented (Yang et al.,1997; Hung et al., 1997; Lutsenko and Cooper, 1998; Schaefer et al., 1999a; Forbes and Cox, 2000; Vanderwerf et al., 2001). As a negative control, we used rat liver.

\section{Western Blot analysis}

Human hepatoma HepG2 cells were maintained in Dulbecco's medium, (DMEM plus Glutamax I, Invitrogen, Milano, Italy) supplemented with penicillin, streptomycin and 10\% heat-inactivated fetal calf-serum (FCS, Gibco BRL) in a humidified atmosphere of $5 \% \mathrm{CO}_{2} / 95 \%$ air, at $37^{\circ} \mathrm{C}$.

Cell lysates were obtained by homogenization with lysis buffer (1X PBS, 1\% IGEPAL, 0.5\% sodium desoxycholate, $0.1 \%$ SDS with $100 \mu \mathrm{g} / \mathrm{mL}$ phenylmethylsulfonyl fluoride (PMSF), $300 \mu \mathrm{g} / \mathrm{mL}$ aprotinin and $100 \mu \mathrm{g} / \mathrm{mL}$ sodium orthovanadate). Several protease inhibitors were added to the buffer to minimize protein degradation during the isolation protocol. Extracts were incubated for 30 min on ice and centrifuged at $12,000 \mathrm{rpm}$ at $4^{\circ} \mathrm{C}$, and the supernatants were recovered. Protein concentration of the total extracts was determined by 

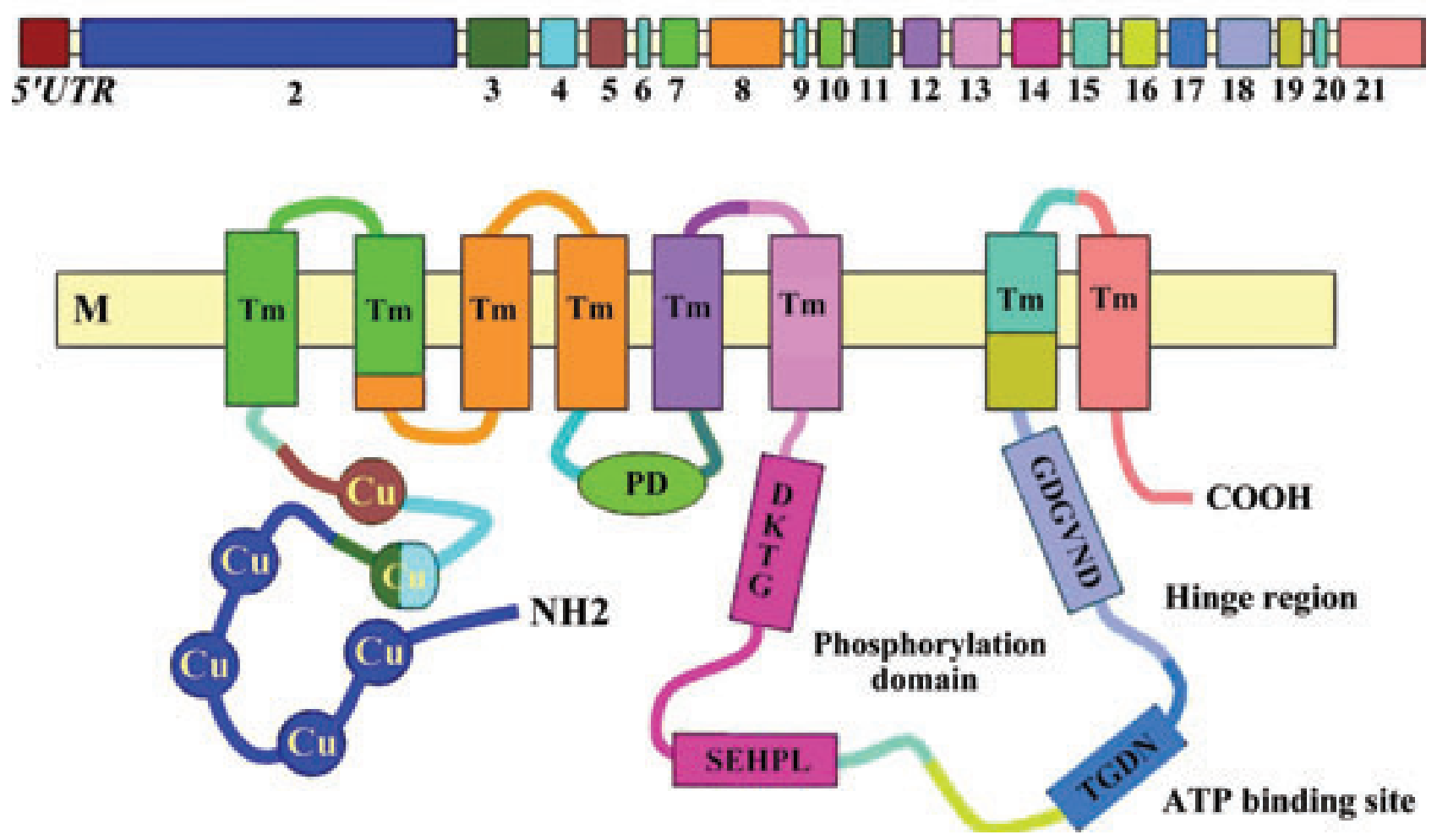

Figure 1. Schematic representation of Wilson's gene and protein. 5'UTR: promoter region. 2-3-4-5-6-7-8-9-10-11-12-13-14-15-16-17-1819-20-21: exons separated by introns. M: phospholipidic bilayer of the membrane. Cu: the metal-binding domains of the trasmembrane cation channel. Tm: trans-membrane domains. PD: phosphatase domain. DKTG, TGDN, GDGVND: amino acid sequences corresponding to functional domains, DKTG corresponds to the aspartyl kinase domain; TGDN and GDGVND to the ATP-binding domains. SEHPL: amino acid sequence containing the most frequently found mutation in WND patients (H 1069 Q).

the method of Bradford (1976) using bovine serum albumin as standard (DC Protein Assay, Bio Rad Laboratories, Hercules, CA, USA). For immunoblotting analysis, from 50 to $200 \mu \mathrm{g} /$ lane of proteins were electrophoresed on SDS-8\% polyacrylamide gel. After gel electrotransfer onto nitrocellulose membranes (MSI), at $300 \mathrm{~mA}$ overnight to ensure equivalent protein loading and transfer in all lanes, the membranes and gels were stained with $0.5 \%$ (w/v) Ponceau S red (ICN Biomedicals, Irvine, CA, USA) in $1 \%$ acetic acid for $5 \mathrm{~min}$, and with Coomassie blue (ICN Biomedicals, Irvine, CA, USA) in $10 \%$ acetic acid for 30 min, respectively. Before staining, gels were fixed in $25 \%(\mathrm{v} / \mathrm{v})$ isopropanol and $10 \%$ acetic acid (Sigma-Aldrich., Milan, Italy). After blocking in TBS containing 0.5\% Tween 20 (Sigma-Aldrich) and 5\% non-fat dry milk overnight at $4^{\circ} \mathrm{C}$, membranes were washed in TBS-T and incubated with ATP7B antiserum, diluted 1:500 in blocking buffer, for two hours. Then, the filter was incubated with anti-rabbit horseradish peroxidase-conjugated IgG (Santa Cruz Biotechnology, Santa Cruz, CA, USA), diluted 1:1000, for 90 min. Immunoreactive bands were identified with a chemiluminescence detection system as described by the manufacturer (Supersignal Substrate, Pierce, Rockford, IIl., USA).

\section{Cell culture}

Studies were carried out using the human cell lines HepG2 (ICLC HTL95005), which were obtained from the Istituto Nazionale per la Ricerca sul Cancro c/o CBA (ICLC, Genova). The culture medium used for this purpose was a mixture of MEM (EBSS), 10\% FBS, 2mM L-Gglutamine, $1 \%$ non-essential amino acids; split confluent cultures 1:3-1:6 using trypsin/EDTA; seed at 2-3 $x$ $10^{4} \mathrm{cells} / \mathrm{cm}^{2} ; 37 \mathrm{C}, 5 \% \mathrm{CO}_{2}$.

For the experimental procedure, Hep-G2 cells were plated on glass coverslips, grown for $24 \mathrm{~h}$, fixed in 4\% paraformaldhyde in PBS for 20 min, quenched with 0.1 ethanolamine, and permeabilized 


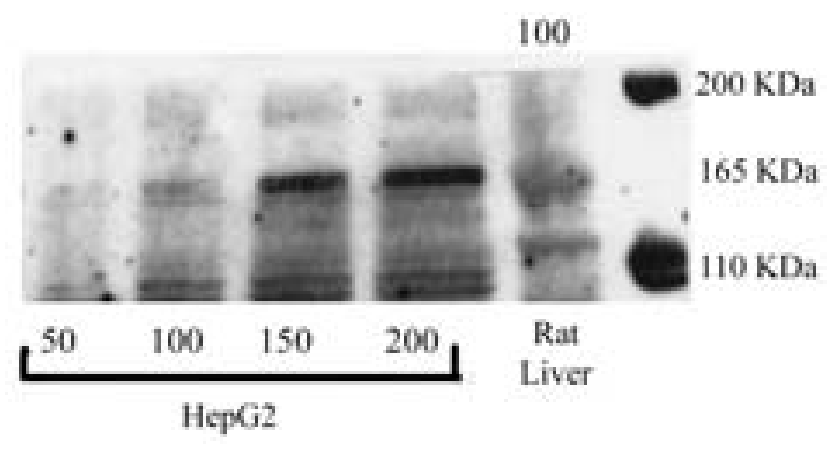

Figure 2. Western Blot analysis identified a single $165 \mathrm{kDa}$ protein in lysates from Hep G2 cells. In rat liver the single 165 kDa protein was not detected.

in $0.2 \%$ triton $X-100$ in PBS for 10 min. Non specific binding was blocked by incubation in $3 \%$ bovine serum albumin in PBS for 30 min. Immunohistochemistry was performed as indicated for snap-frozen section.

\section{Results}

Western Blot Analysis identified a single 165 kDa protein in lysates from Hep G2 cells. The single $165 \mathrm{kDa}$ protein was not detected in rat liver (Figure 2). Previous papers showed that ATP7B is a $165 \mathrm{kDa}$ protein expressed in HepG2 cells (Yang et al.,1997; Hung et al., 1997; Lutsenko and Cooper, 1998; Schaefer et al., 1999a; Forbes and Cox, 2000; Vanderwerf et al., 2001). Immunoblotting experiments were performed using our antibody specific recognizing the P-type ATPase, ATP7B. These data indicate that ATP7B is abundantly expressed as a single-chain protein in HepG2 and that the antibody to ATP7B does not detect the homologous transporter in rat liver.

Immunohistochemistry. No immunoreactivity for ATP7B was detected in the rat liver (negative control) either in hepatocytes or in epitelial biliary cells (Figure 3).

In HepG2 cells (positive control), ATP7B was constantly detected in a perinuclear location. Immunoreactivity appeared as a roundish spot, consistent with the location of ATP7B in the Golgi apparatus (Figure 4a). A variable degree of immunoreactivity for ATP7B was also observed close to the cell membrane and scattered in the cytoplasm of some tumor cells (Figure $4 b$ ).

In all ten human normal livers studied, immunoreactivity for ATP7B was detected in the hepatocytes and in the biliary cells (Figure $4 c-d-e-f$ ). In the

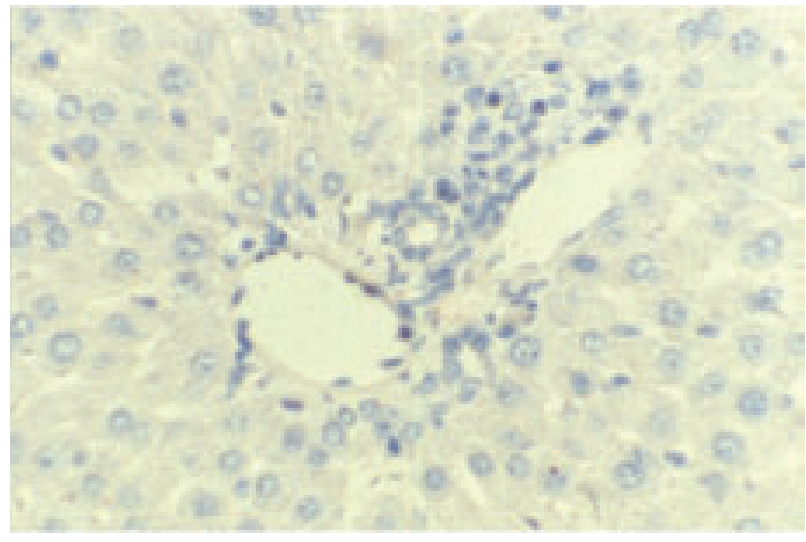

Figure 3. Rat liver (negative control): no immunoreactivity for ATP7B was detected either in hepatocytes or in epitelial biliary cells. (250X)

hepatocytes, ATP7B was predominantly distributed at the periphery of the cell, close to the cell membrane, with a linear or with a granular pattern (Figure $4 \mathrm{c}$-e-f). The majority of hepatocytes showed this immunoreactivity pattern for ATP7B: in some hepatocytes, immunoreactivity for ATP7B appeared stronger at the biliary pole, but the protein was constantly observed even at the sinusoidal pole. We did not observe any clear evidence of ATP7B localization in the Golgi apparatus or in cytoplasmic vesicles. No significant difference in immunoreactivity among various acinar zones was found (Figure 4c-e-f). Immunoreactivity for ATP7B was also detected in cells lining the bile ducts (Figure 4c-d): it appeared in a linear pattern and was often more pronounced at the basal pole of biliary cells. Sinusoidal cells never were found to express ATP7B.

We observed some differences in the degree of immunoreactivity for ATP7B among different livers: in the majority of cases, ATP7B was homogeneously detected in almost all the hepatocytes and in all bile ducts; in other cases, immunolocalization of the protein was restricted to groups of hepatocytes and to a part of biliary structures. In these cases, we frequently observed, in the same bile duct, cells immunoreactive for ATP7B adjacent to negative cells. No clear evidence of a zonal distribution was found. In livers with the highest level of immunoreactivity, ATP7B was detected in the hepatocytes of all acinar zones; in cases with minor degrees of reactivity, positive hepatocytes were observed in acinar zones, often adjacent to negative hepatocytes. 

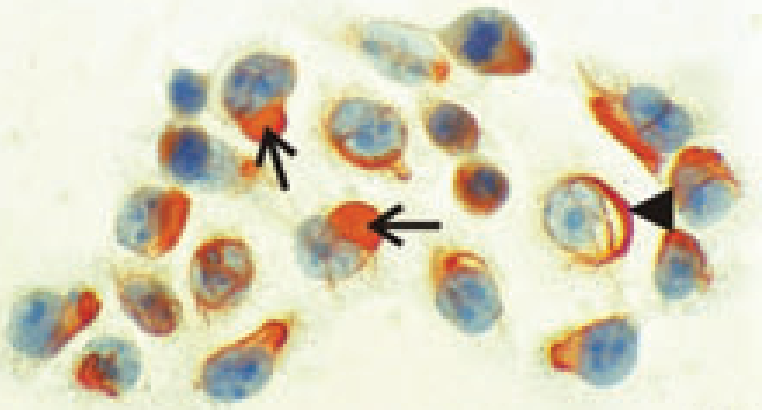

4a
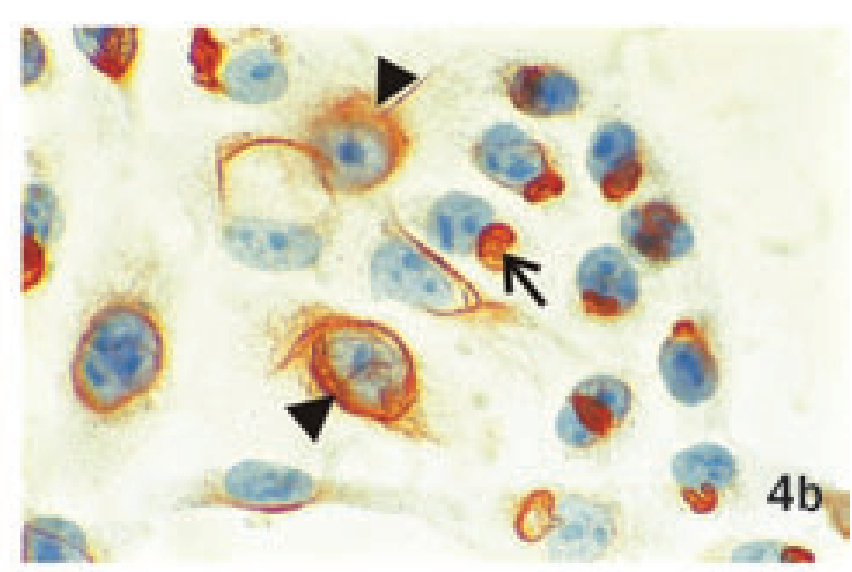
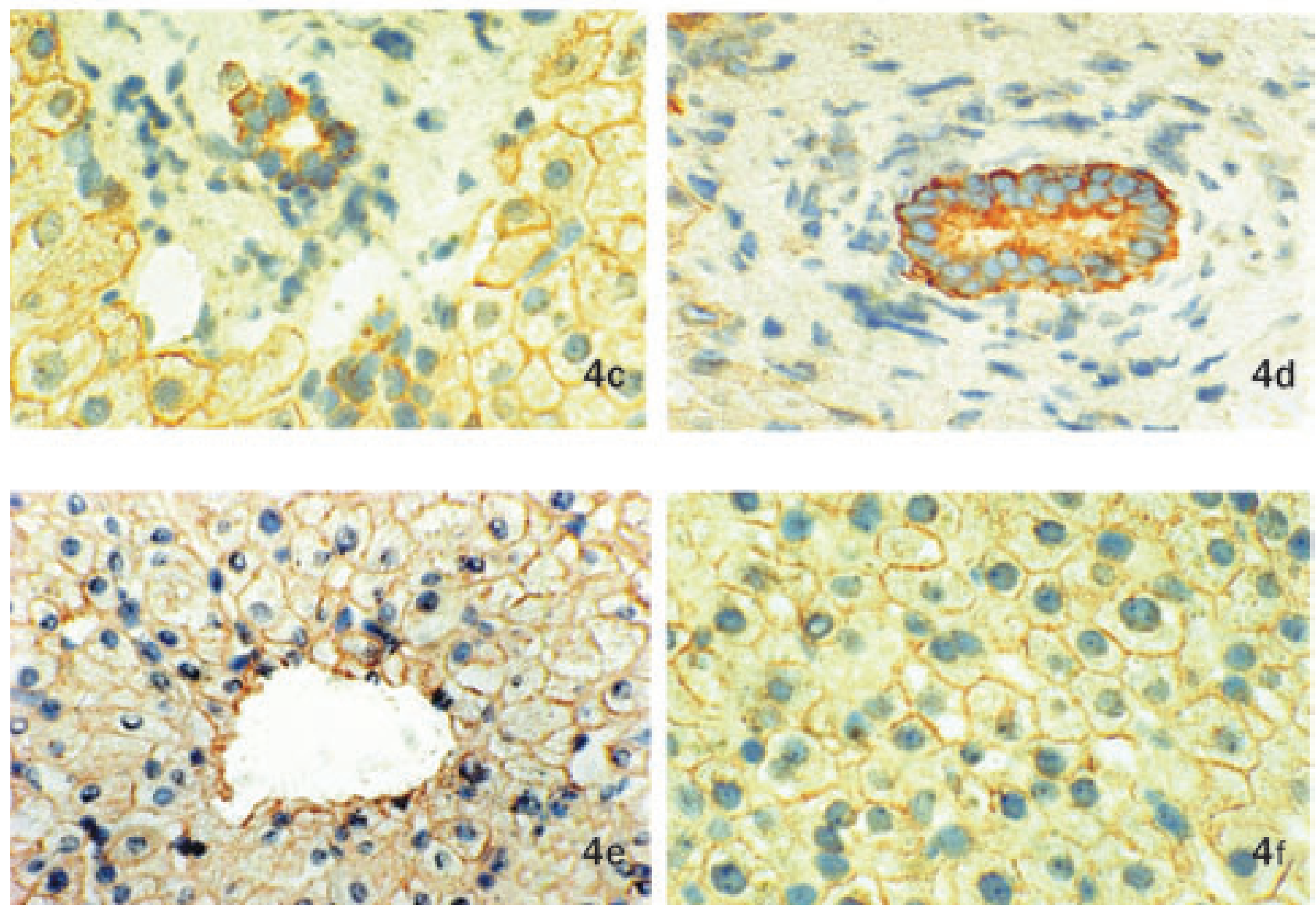

Figure 4. a-b Hep-G2 cells in the steady state (positive control): ATP7B was detected in a perinuclear location, as a roundish spot, consistent with the location of ATP7B in the Golgi apparatus (arrows); in some cells immunoreactivity for ATP7B was also found at the periphery of the cell and in the cytoplasm (arrowheads). c-d-e-f Normal human liver: periportal zone (c); bile duct (d); pericentral zone (e); intracinar zone (f). Immunoreactivity for ATP7B was observed in hepatocytes and biliary cells (c). In the hepatocytes, ATP7B is localized at the periphery of the cell, in the plasma membrane, with a linear or with a granular pattern; the predominat localization is found at the biliary pole of the cell, but the protein is also observed at the sinusoidal pole. No difference in ATP7B immunoreactivity is evident among zone 1 (c), zone 3 (d), and zone 2 (e) of the acinus. Biliary epithelial cells show a homogeneous immunoreactivity for ATP7B (c, d). (400X). 


\section{Discussion}

Knowledge of copper trafficking in the liver has dramatically increased in recent years after the discovery of the Menkes (Vulpe et al., 1993) and the Wilson disease genes (Tanzi et al., 1993). Despite the many studies carried out on ATP7B, the exact localization of this protein is controversial. On the basis of previous studies on experimental models, it has been claimed that ATP7B is localized in mitochondria (Lutsenko and Cooper, 1998), trans-Golgi network (Hung et al., 1997; Yang et al., 1997) of HepG2 cells, late endosomes in Huh7 cells (Harada et al., 2000 ab; Harada et al., 2001), transfected HEK293, Hep3B and OUMS29 cells (Harada et al., 2003), rat liver microsomes (Bingham et al., 1996) and in the plasma membrane in hepatocytes of LEC rats (Nagano et al; 1998). Immunohistochemical studies in HepG2 culture (Hung et al., 1997) and in transfected CHO cells (Forbes and Cox, 2000), have also shown the ability of ATP7B to change its localization and its function according to the copper status of the cell; in fact, in these cell lines, the authors have shown that the protein may redistribute from the trans-Golgi network to the cytoplasmic peripheral compartment when cells are exposed to elevated copper levels. Other studies in Huh7 cell lines (Harada et al; 2000a) and in transfected HEK293, Hep3B and OUMS29 cells have suggested that ATP7B is localized in the late endosomes in both copper-depleted and copper-loaded conditions. Conflicting results on ATP7B localization have been shown by studies carried out on human liver tissue: according to Schaefer et al (1999b), ATP7B is predominantly present in the pericanalicular area of the hepatocytes, which probably represent the trans-Golgi vesicles, while only small amounts of the protein are localized to the canalicular membrane. In another recent study (Huster et al., 2003) using immunogold electron microscopy in human liver tissue, ATP7B was found to be restricted to transGolgi vesicles, while endoplasmic reticulum and the whole cell membrane, including bile canaliculi, were devoid of immunolabeling for ATP7B.

Our data show that the intracellular distribution of ATP7B in human liver is different from that observed in in vitro systems. Moreover, some differences have also been found with previous studies on human livers. In all 10 human livers observed in our study, ATP7B was predominantly detected close to the cell membrane of the hepatocytes, with a preferential localization to the biliary pole. This observation confirms that of Schaefer et al (1999b), who were the only authors to demonstrate a canalicular membrane distribution pattern of ATP7B in human liver. In addition, we found that the protein is detectable even at the sinusoidal pole of the hepatocytes.

A previously unknown distribution of ATP7B in the human liver appears evident in our study. In fact, in almost all the liver sections examined, the protein was not restricted solely to the hepatocytes, but was also present in biliary cells, while no signal was observed in biliary ducts by Schaefer et al (1999b).

Our data on the distribution of ATP7B may help to improve our understanding of the physiological role of this copper pump in the human liver. Its localization in biliary cells leads us to the hypothesis that the role that this copper pump plays in the excretion/re-uptake of the metal in the liver is not restricted to the hepatocytes. In the hepatocytes, the predominant immunolocalization of ATP7B at the cell membrane is in favour of a predominant role for ATP7B in the regulation of copper concentration inside the cell. The presence of the protein also at the sinusoidal pole of the hepatocytes, a localization previously unknown, could be at the basis of a role of ATP7B not only in copper elimination through the bile canaliculus, but also in the traffic of copper atoms in the Disse spaces and, presumably, in copper uptake from the blood stream. The absence, in our series, of immunolocalization of ATP7B in the Golgi apparatus may indicate that the putative role of the protein in incorporating copper atoms into ceruloplasmin or in other copper proteins is quantitatively less relevant than in hepatoma cell lines.

Given the discrepancy between our results in the normal human liver in vivo and the previous studies carried out in neoplastic liver cells in vitro, further studies appear to be mandatory in order to clarify the localization and the physiological role of ATP7B in man, in health and in disease.

\section{Acknowledgements}

The authors wish to thank Prof. Massimo Castagnola (Catholic University of Rome) for his helpful criticism of the manuscript. The expert photographic assistance of Mr. Alessandro Cadau, the technical assistance of Ms. Beatrice Loi and the 
secretarial assistance of Ms. Mariangela Picciau are also kindly acknowledged.

\section{References}

Bingham MJ, Ong TJ, Ingledew WJ, McArdle HJ. ATP-dependent copper transporter in the Golgi apparatus of rat hepatocytes, transports CuII not CuI. Am J Physiol 1996; 271: G741-6.

Bradford $M$. A rapid and sensitive method for the quantitation of microgram quantities of protein using the principle of protein-dye binding. Anal Biochem 1976; 72: 248-54.

Faa G, Nurchi V, Demelia L, Ambu R, Parodo G, Congiu T, et al. Uneven hepatic copper distribution in Wilson's disease. Hepatol 1995; 22: 303-8.

Forbes JR, His G, Cox DW. Role of copper-binding domain in the copper transport function of ATP7B, the P-type ATPase defective in Wilson disease. J Biol Chem 1999; 274: 12408-13.

Forbes JR, Cox D. Copper-dependent trafficking of Wilson disease mutant ATP proteins. Human Molecular Genetics 2000; 9: 192735.

Gitlin JD. Wilson disease. Gastroenterology 2003; 125: 1868-77.

Hamza I, Faisst A, Prohaska J, Chen J, Gruss P, Gitlin JD. The metallochaperone ATOXI plays a critical role in perinatal copper homeostasis. PNAS 2001; 98 : 6848-52.

Harada M, Sakisaka S, Kawaguchi T, Kimura R, Taniguchi E, Koga H, et al. Copper does not alter the intracellular distribution of the ATP7B, a copper-trasporting ATPase. Biochem Biophys Res Commun 2000a; 275: 871-6.

Harada M, Sakisaka S, Terada K, Kimura R, Kawaguchi T, Koga H, et al. Role of ATP7B in biliary copper excretion in a human hepatoma cell line and normal rat hepatocytes. Gastroenterology 2000b;118: 921-8.

Harada M, Sakisaka S, Terada K, Kimura R, Kawaguchi T, Koga H, et al. A mutation of the Wilson disease protein, ATP7B, is degraded in the proteasomes and forms protein aggregates. Gastroenterology 2001; 120: 967-74.

Harada M, Kumemura H, Sakisaka S, Shishido S, Taniguchi E, Kawaguchi T, et al. Wilson disease protein ATP7B is localized in the late endosomes in a polarized human hepatocyte line. Int $\mathrm{J}$ Mol Med 2003; 11: 293-8.

Hou ZJ, Narindrasorasak S, Bhushan B, Sarkar B, Mitra B. Functional analysis of chimeric proteins of the Wilson $\mathrm{Cu}(\mathrm{I})$-ATPase (ATP7B) and $\mathrm{ZntA}, \mathrm{a} \mathrm{Pb}$ (II)/Zn(II)/Cd(II)-ATPase from Escherichia coli. J Biol Chem. 2001; 276: 40858-63.

Hung IH, Suzuki M, Yamaguchi Y, Yuan DS, Klausner RD, Gitlin JD. Biochemical characterization of the Wilson disease protein and functional expression in the yeast Saccaromices cerevisiae. J Biol Chem 272: 21461-6.

Hung IH, Casareno RLB, Labesse G, Mathews FS, Gitlin JD. HAHI is a copper-binding protein with distinct amino acid residues mediating copper homeostasis and antioxidant defense. JBC 2002; 273: 1749.

Huster D, Hoppert M, Lutsenko S, Zinke J, Lehmann C, Mossner J, et al. Defective cellular localization of mutant ATP7B in Wilson's disease patients and hepatoma cell lines. Gastroenterology 2003; 124:
335-45.

Larin D, Mekios C, Das K, Ross B, Yang AS, Gillian C. Characterization of the interaction between the Wilson and Menkes disease proteins and the cytoplasmic copper chaperone HAHIp. J Biol Chem 1999; 40: 28497-504.

Lutsenko S, Kaplan JH. Organization of P-type ATPase: significance of structural diversity. Biochemistry 1995; 34: 15607-13.

Lutsenko S, Cooper M. Localization of the Wilson's disease protein product to mitocondria. Biochemistry 1998; 95: 6004-9.

Lutsenko S, Tsivkovskii R, Walker JM. Functional properties of human copper-transporting ATPase ATP7B (the Wilson's disease protein) and regulation by metallochaperone ATOX1. Annals NY Acad Sci 2003; 986: 204-11.

Moore S, Cox D. Expression in mouse kidney of membrane copper transporters ATP7A and ATP7B. Nephron 2002; 92: 629-34.

Nagano K, Nakamura K, Urakami KI, Umeyana K, Uchiyama H, Koiwai $K$, et al. Intracellular distribution of the Wilson's disease gene product (ATPase7B) after in vitro and in vivo exogenous expression in hepatocytes from the LEC rat, an animal model of Wilson's disease. Hepatology 1998; 27:799-807.

Petrukhin K, Lutsenko S, Chernov I, Ross BM, Kaplan JH, Gillian TC. Characterization of the Wilson disease gene encoding a P-type copper transporting ATPase: genomic organization alternative spicing, and structure/function predictions. Hum Mol Genet 1994; 3:164756.

Riordan SM, Williams R. The Wilson's disease gene and phenotypic diversity. J Hepatol 2001; 34: 165-71.

Roelofsen H, Wolters H, Van Luyn MJA, Miura N, Kuipers F, Vonk RJ. Copper-induced trafficking of ATP7B in polarized hepatoma cells provides a mechanism for biliary copper excretion. Gastroenterology 2000; 119:782-93.

Schaefer M, Hopkins RG, Failla ML, Gitlin JD. Hepatocyte-specific localization and copper-dependent trafficking of the Wilson's disease protein in the liver. Am J Physiol 1999a; 276: G639-G646.

Schaefer M, Roelofsen H, Wolters H, Hofmann WJ, Muller M, Kuipers $F$, et al. Localization of the Wilson's disease protein in human liver. Gastroenterology 1999b; 117: 1380-5.

Tanzi RE, Petrukhin KE, Chernov I, Pellequer JL, Wasco W, Ross B, et al. The Wilson disease gene is a copper transporting ATPase with homology to the Menkes disease gene. Nature Genet 1993; 5: 34450.

Terada K, Schilsky ML, Miura N, Sugiyama T. ATP (WND) Protein. Int J Biochem Cell Biol 1998; 30: 1063-7.

Vanderwerf SM, Cooper MJ, Stetsenko IV, Lutsenko S. Copper specifically regulates intracellular phosphorylation of the Wilson's disease protein, a human copper-transporting ATPase. J Biol Chem. 2001; 276: 36289-94

Vulpe C, Levinson B, Whitney S, Packman S, Gitschier J. Isolation of a candidate gene for Menkes disease and evidence that it encodes a copper-transporting ATPase. Nat Genet 1993; 3: 7-13.

Yang X, Miura N, Kawarada Y, Terada K, Petrukhin K, Gilliam C, et al. Two forms of Wilson disease protein produced by alternative splicing are localized in distinct cellular ompartments. Biochem J 1997; 326: 897-902.

Yamada T, Agui T, Suzuki Y, Sato M, Matsumoto K. Inhibition of copper incorporation into ceruloplasmin leads to the deficiency in serum ceruloplasmin activity in Long-Evans Cinnamon mutant rats. J Biol Chem 1993; 268: 8965-71. 
D. Fanni et al. 